\title{
Upper gastrointestinal haemorrhage and deprivation: a nationwide cohort study of health inequality in hospital admissions
}

\author{
Colin J Crooks, ${ }^{1,2}$ Joe West, ${ }^{1,2}$ Tim R Card $^{1,2,3}$
}

\begin{abstract}
- Additional tables are published online only. To view these files please visit the journal online (http://gut.bmj. com/content/61/4.toc).

1 Division of Epidemiology and Public Health, The University of Nottingham, Nottingham City Hospital, Nottingham, UK

${ }^{2}$ Nottingham Digestive Diseases Centre National, Institute for Health Research Biomedical Research Unit, Queen's Medical Centre, Nottingham University Hospitals National Health Service Trust, Nottingham, UK ${ }^{3}$ Sherwood Forest Hospitals National Health Service Trust, Mansfield, UK
\end{abstract}

\section{Correspondence to} Colin J Crooks, Division of Epidemiology and Public Health, The University of Nottingham, Clinical Sciences Building 2 Nottingham City Hospital, NG5 1PB, UK; colin.crooks@ nottingham.ac.uk

Revised 10 June 2011 Accepted 13 June 2011 Published Online First 13 July 2011
Objective Inequalities in health are well recognized in cardiovascular disease and cancer, but in comparison, we have minimal understanding for upper gastrointestinal bleeding. Since furthering our understanding of such inequality signposts preventable disease, we investigated in detail the association between upper gastrointestinal bleeding and socioeconomic status.

Design Population-based cohort study.

Setting All English National Health Service hospitals. Population English adult population, 1 January 2001 to 31 December 2007.

Exposure measures Deprivation scores defined according to quintiles of neighbourhood areas ranked by the Indices of Multiple Deprivation for England 2007.

Outcome measures Rates of all adult admissions coded with a primary diagnosis of upper gastrointestinal bleed were analysed by deprivation quintile and adjusted for age, sex, region and year using Poisson regression. Results The annual hospitalization rate for non-variceal haemorrhage was 84.6 per 100000 population $(95 \% \mathrm{Cl}$ 83.5 to $84.1 ; n=237145$ ), and for variceal haemorrhage, it was 2.83 per 100000 population (95\% Cl 2.87 to 2.99 ; $n=8291$ ). There was a twofold increase in the hospitalization rate ratio for non-variceal haemorrhage from the most deprived areas compared to the least deprived (2.00, 95\% $\mathrm{Cl} 1.98$ to 2.03). The ratio for variceal haemorrhage was even more pronounced (2.49, 95\% Cl 2.32 to 2.67). Inequality increased over the study period (non-variceal $p<0.0001$, variceal $p=0.0068$ ), and adjusting for age and sex increased the disparity between deprived and affluent areas. Case fatality did not have a similar socioeconomic gradient.

Conclusion Both variceal and non-variceal haemorrhage hospitalization rates increased with deprivation, and there was a similar gradient in all areas of the country and in all age bands. The existence of such a steep gradient suggests that there are opportunities to reduce hospitalizations down to the low rates seen in the most affluent, and thus, there is the potential to prevent almost 10000 admissions and over 1000 deaths a year.

\section{INTRODUCTION}

The increased health risks associated with deprivation are well described in cancer and heart disease, ${ }^{1}$ but the association with other diseases is less well known. If we are to make inroads into the health care burden related to inequality, then one of the first tasks is to identify diseases with strong socioeconomic gradients that have identifiable and

\section{Significance of this study}

What is already known on the subject?

- Identifying disease that is related to deprivation helps to signpost preventable disease, but studies on deprivation have mainly focused on cardiovascular disease, cancer and mental health.

- Upper gastrointestinal bleeding is the commonest acute admission to gastroenterology, and its causes are potentially preventable.

- We have minimal understanding of its socioeconomic distribution by region, age, variceal and non-variceal causes and the associated excess mortality.

\section{What are the new findings?}

- This study demonstrates that people from areas of high deprivation have up to three times the rate of upper gastrointestinal haemorrhage hospitalization compared to people from more affluent areas. This gradient was not explained by random error or differences in age, sex, year, severity or region and was present in both variceal and non-variceal haemorrhage.

- Case fatality did not have a similar gradient, suggesting that the inequalities were not explained by differences in the severity of the presenting admissions.

- To reduce the burden of upper gastrointestinal haemorrhage, inequalities from deprivation need to be understood and modified prior to hospital admission.

How might it impact on clinical practice in the foreseeable future?

- If the whole population experienced the same levels of risk as the most affluent, we estimate that up to 10000 admissions, costing a total of at least $£ 20$ million, and over 1000 deaths could be prevented each year in England.
This paper is freely available online under the BMJ Journals unlocked scheme, see http:// gut.bmi.com/site/about/ unlocked.xhtml modifiable risk factors. Upper gastrointestinal bleeding may well be one of these diseases; for example, Helicobacter pylori can be eradicated, the consumption of alcohol reduced, and the prescribing of nonsteroidal anti-inflammatory drugs (NSAIDs) curtailed. There is also some prior, albeit limited, evidence of a socioeconomic gradient in this disease from two studies from the UK. A small study of less than 2000 patients from the 
northwest of Scotland demonstrated a twofold difference in the occurrence of upper gastrointestinal haemorrhage between the least and most deprived, while a recent report from Wales also indicated that those from most deprived areas have the highest rate of hospitalization for upper gastrointestinal haemorrhage. ${ }^{2}$ However, both these studies found higher hospitalization rates than did previous studies, and this raises questions of how their populations and cases were defined. Furthermore, both studies only reported crude combined variceal and non-variceal haemorrhage estimates, and their methodology and limited size mean that they did not investigate whether differences in age, gender, year or region might be responsible for socioeconomic gradients.

We therefore aimed to accurately estimate the hospitalization rates for upper gastrointestinal haemorrhage and its relation to socioeconomic status while adjusting for differences in age, sex, region, severity and year. To achieve this, we used 7 years of all hospital admissions in the whole population of England.

\section{METHODS \\ Study design}

A retrospective cohort study was designed for the whole English population using the Hospitals Episode Statistics (HES) database to identify upper gastrointestinal bleeds. The HES contains information on all admissions to National Health Service (NHS) hospitals in England, with over 12 million new records added each year. It is managed by the NHS information centre and is available for research with ethical approval. Available data consist of up to 14 diagnoses for each episode during an admission coded using the International Classification of Diseases, $10^{\text {th }}$ Revision and up to 12 procedures coded using the UK Tabular List of the Classification of Surgical Operations and Procedures (version OPCS4).

\section{Population}

Midyear estimates of the English population over 16 years old between 2001 and 2007 were obtained from the Office of National Statistics (ONS) website under crown copyright by age, sex and lower super output area. Lower super output areas included around 400 homes and defined a consistent geographical area over the time of this study.

\section{Admissions for gastrointestinal haemorrhage Inclusion criteria}

All admissions in patients 16 years and older who had a primary diagnosis of upper gastrointestinal haemorrhage in the admission episode between 1 January 2001 and 31 December 2007 were extracted. Upper gastrointestinal haemorrhage was defined as an International Classification of Diseases, $10^{\text {th }}$ Revision code that specifically implied either variceal gastrointestinal bleeding (oesophageal varices with bleeding (I85.0)) or non-variceal haemorrhage (Mallory-Weiss syndrome (K22.6), oesophageal haemorrhage (K22.8), acute or chronic gastric ulcer with haemorrhage including perforation with haemorrhage (K25.0, K25.2, K25.4, K25.6), acute or chronic duodenal ulcer with haemorrhage including perforation with haemorrhage (K26.0, K26.2, K26.4, K26.6), acute or chronic peptic ulcer with haemorrhage including perforation with haemorrhage (K27.0, $\mathrm{K} 27.2$, K27.4, K27.6), acute or chronic gastrojejunal ulcer with haemorrhage including perforation with haemorrhage (K28.0, K28.2, K28.4, K28.6), haematemesis (K92.0), melaena (K92.1) or unspecified gastrointestinal haemorrhage (K92.2)). Additional codes that were associated with a non-variceal bleed code were also extracted to identify aetiological subgroups. Subsequent readmissions with upper gastrointestinal haemorrhage were included in the study.

\section{Exclusion criteria}

The study population was geographically limited to patients who were resident within England at the time of hospital admission. Admissions were excluded if they were coded with unspecified gastrointestinal haemorrhage (K92.2) but had a lower gastrointestinal endoscopy/diagnosis code with no upper gastrointestinal endoscopy code. Episodes with the following were excluded: day case admission codes with no overnight stay (the majority of these admissions were for an outpatient endoscopy), inpatient bleeds with a bleeding code later than the initial admission date, invalid or missing date codes as flagged by HES, date codes that were out of chronological order, invalid or missing date of birth codes, invalid or missing gender codes or duplicate records for one episode.

\section{Exposure measurements}

The exposure of interest was the socioeconomic status of the lower super output area of residence (that include about 400 houses) at the time of admission. Lower super output areas from the whole country were grouped into quintiles, from the least deprived to the most deprived, by their ranking in the Indices of Multiple Deprivation for England 2007. ${ }^{4}$ The English indices of multiple deprivation are derived from 38 indicators grouped into seven empirically weighted domains that are used to rank lower super output areas from the least to most deprived. The seven domains and their weights are income deprivation (22.5\%) based on government benefits; employment deprivation (22.5\%) based on government benefits and allowances; health deprivation and disability $(13.5 \%)$ based on a number of health measures; education, skills and training deprivation (13.5\%) based on participation and attainment; barriers to housing and services $(9.3 \%)$ based on local amenities and rehousing rates; crime (9.3\%) based on recorded crime levels and living environment deprivation (9.3\%) based on housing quality, air quality and traffic accidents. Their indicators are listed and discussed in detail in The English Indices of Deprivation 2007. ${ }^{4}$

Other exposures of age, sex, region and year of gastrointestinal haemorrhage were extracted as potential confounders. The recorded age was grouped into age bands for men of 16-29, $30-44,45-64$ and $\geq 65$ years and for women of $16-29,30-44$, $45-59$ and $\geq 60$ years. These age bands were chosen as those available in denominator data and reflected UK retirement ages at the time. Region was defined by the Regional Government Office of the home residence at time of admission. Year was assessed as a categorical and a continuous variable.

\section{Mortality}

Short-term mortality was defined as a date of death within 28 days of the start of the recorded episode of upper gastrointestinal haemorrhage. This included deaths that occurred after discharge from hospital but within the 28 days. The date and fact of death were obtained from the ONS death register using a probability matching algorithm based on NHS number, date of birth, postcode and sex. ${ }^{5}$

\section{Statistical analysis}

We analysed variceal and non-variceal haemorrhage admissions separately. After the exclusions described above, hospitalization rates were calculated by quintiles of socioeconomic status, age group, sex, region and year. Poisson regression was used to adjust 
the hospitalization rates by socioeconomic status for each of these potential confounders. Variables that changed the incidence rate ratios (RRs) were judged to be confounders and remained in the model. We examined whether the effect of socioeconomic status changed by year by including interaction terms between socioeconomic status and year. Logistic regression was used to adjust ORs for 28-day mortality in each deprivation quintile for age, sex and year of admission. All analyses were performed using Stata V. 11 (Stata Corp., College Station, Texas, USA).

\section{Subgroup and sensitivity analysis}

We repeated the analyses for aetiological subgroups of non-variceal upper gastrointestinal haemorrhage (gastritis/duodenitis, Mallory-Weiss syndrome, oesophagitis, gastric ulcer, duodenal ulcer and malignancy) to determine whether relationships seen were specific to one or more of them. We then performed four sensitivity analyses. First, to assess the possibility of underreporting, we expanded the definition for variceal haemorrhage to include all admissions coded for oesophageal haemorrhage (K22.8) and then reassessed the socioeconomic gradient. Second, to assess the effect of possible over-reporting, we restricted the definition of non-variceal haemorrhage to admissions with either an associated coded intervention or outcome, which we defined as an endoscopy, blood transfusion or death within 14 days of the recorded bleed date. We then reanalysed this restricted cohort of upper gastrointestinal bleeds for socioeconomic gradients. Third, we assessed whether any gradients differed when the analysis was restricted to either the first admission or a subsequent readmission for each patient. Finally, we examined whether restricting the analysis to patients with no previous recording of alcohol-related diseases altered any gradients we found.

\section{RESULTS}

Two hundred and forty-five thousand four hundred and thirtyeight primary admissions for upper gastrointestinal haemorrhage were identified; $97 \%$ were coded as non-variceal haemorrhage, and $3 \%$, as variceal haemorrhage (see figure 1 for exclusions and missing or invalid data). The average annual hospitalization rate for non-variceal haemorrhage was 83.8 per 100000 population (95\% CI 83.5 to 84.1 ), and for variceal haemorrhage, it was 2.93 per 100000 population (95\% CI 2.87 to 2.99). The crude socioeconomic gradient between the most and least deprived quintiles was greater for variceal haemorrhage

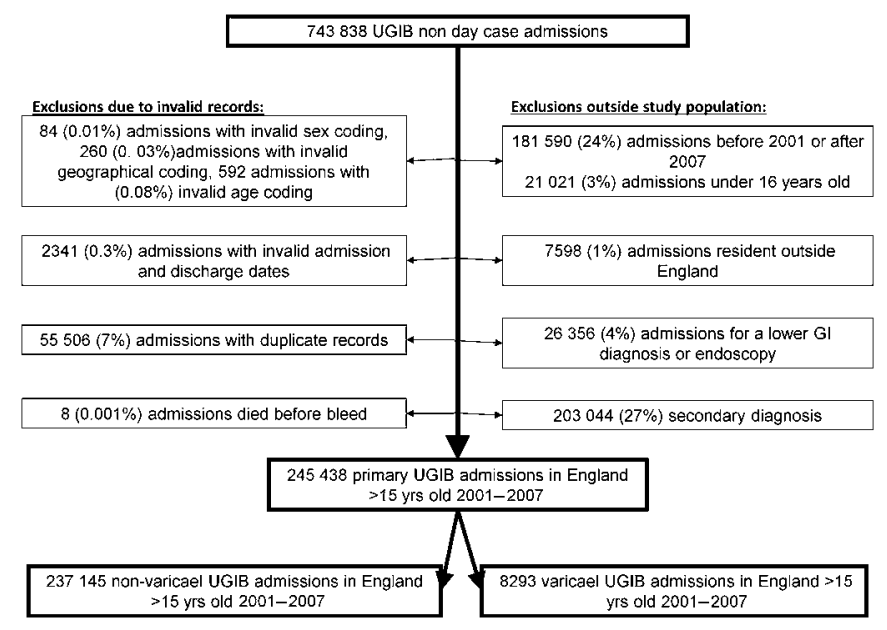

Figure 1 Flow chart of exclusions from study.
Table 1 Incidence and number by year, gender and age for nonvariceal haemorrhage

\begin{tabular}{|c|c|c|c|c|c|}
\hline Variable & $\begin{array}{l}\text { Upper non-variceal } \\
\text { gastrointestinal } \\
\text { haemorrhage } \\
\text { admissions (n) }\end{array}$ & $\begin{array}{l}\text { Hospitalizations } \\
\text { per } 100000 \\
\text { population } \\
\text { per year }\end{array}$ & $\begin{array}{l}\text { Crude } \\
\text { RR }\end{array}$ & $\begin{array}{l}\text { Adjusted } \\
\text { RR } \dagger\end{array}$ & $\begin{array}{l}\text { Adjusted } \\
95 \% \mathrm{CI}\end{array}$ \\
\hline \multicolumn{6}{|c|}{ Quintile of deprivation } \\
\hline $\begin{array}{l}1=\text { Least } \\
\text { deprived }\end{array}$ & 34256 & 59.8 & 1 & 1 & \\
\hline 2 & 41224 & 71.4 & 1.19 & 1.18 & 1.16 to 1.20 \\
\hline 3 & 45252 & 78.5 & 1.31 & 1.33 & 1.31 to 1.35 \\
\hline 4 & 51489 & 91.5 & 1.53 & 1.63 & 1.61 to 1.65 \\
\hline $\begin{array}{l}5=\text { Most } \\
\text { deprived }\end{array}$ & 64924 & 119.9 & 2.00 & 2.22 & 2.20 to 2.25 \\
\hline \multicolumn{6}{|l|}{ Year } \\
\hline 2001 & 32093 & 81.2 & 1 & & \\
\hline 2002 & 32277 & 81.1 & 1.00 & & \\
\hline 2003 & 33626 & 84.0 & 1.03 & & \\
\hline 2004 & 34419 & 85.3 & 1.05 & & \\
\hline 2005 & 35300 & 86.6 & 1.07 & & \\
\hline 2006 & 34948 & 85.1 & 1.05 & & \\
\hline 2007 & 34482 & 83.2 & 1.03 & & \\
\hline \multicolumn{6}{|l|}{ Gender } \\
\hline Male & 132874 & 96.8 & 1 & 1 & \\
\hline Female & 104271 & 71.5 & 0.74 & 0.60 & 0.59 to 0.60 \\
\hline \multicolumn{6}{|c|}{ Age (years) } \\
\hline$<30$ & 22859 & 36.2 & 1 & 1 & \\
\hline $30-44$ & 34556 & 43.8 & 1.21 & 1.26 & 1.24 to 1.28 \\
\hline $45-64^{*}$ & 46462 & 61.2 & 1.69 & 1.77 & 1.74 to 1.80 \\
\hline$\geq 65^{*}$ & 133268 & 204.7 & 5.65 & 6.47 & 6.37 to 6.56 \\
\hline
\end{tabular}

Year and region were not included in the adjusted model.

*Boundary at 60 years for women.

†Adjusted for age and gender.

Table 2 Incidence and number by year, gender and age for variceal haemorrhage

\begin{tabular}{|c|c|c|c|c|c|}
\hline Variable & $\begin{array}{l}\text { Upper variceal } \\
\text { gastrointestinal } \\
\text { haemorrhage } \\
\text { admissions (n) }\end{array}$ & $\begin{array}{l}\text { Hospitalizations } \\
\text { per } 100000 \\
\text { population } \\
\text { per year }\end{array}$ & $\begin{array}{l}\text { Crude } \\
\text { RR }\end{array}$ & $\begin{array}{l}\text { Adjusted } \\
\mathbf{R R} \dagger\end{array}$ & $\begin{array}{l}\text { Adjusted } \\
95 \% \mathrm{Cl}\end{array}$ \\
\hline \multicolumn{6}{|c|}{ Quintile of deprivation } \\
\hline $\begin{array}{l}1=\text { Least } \\
\text { deprived }\end{array}$ & 1084 & 1.9 & 1 & 1 & \\
\hline 2 & 1286 & 2.2 & 1.18 & 1.19 & 1.10 to 1.29 \\
\hline 3 & 1535 & 2.7 & 1.41 & 1.49 & 1.38 to 1.61 \\
\hline 4 & 1833 & 3.3 & 1.72 & 1.93 & 1.79 to 2.08 \\
\hline $\begin{array}{l}5=\text { Most } \\
\text { deprived }\end{array}$ & 2555 & 4.7 & 2.49 & 2.93 & 2.73 to 3.14 \\
\hline \multicolumn{6}{|l|}{ Year } \\
\hline 2001 & 1096 & 2.8 & 1 & & \\
\hline 2002 & 1137 & 2.9 & 1.03 & & \\
\hline 2003 & 1172 & 2.9 & 1.06 & & \\
\hline 2004 & 1267 & 3.1 & 1.13 & & \\
\hline 2005 & 1155 & 2.8 & 1.02 & & \\
\hline 2006 & 1247 & 3.0 & 1.09 & & \\
\hline 2007 & 1219 & 2.9 & 1.06 & & \\
\hline \multicolumn{6}{|l|}{ Gender } \\
\hline Male & 5496 & 4.0 & 1 & 1 & \\
\hline Female & 2797 & 1.9 & 0.48 & 0.47 & 0.45 to 0.49 \\
\hline \multicolumn{6}{|c|}{ Age (years) } \\
\hline$<30$ & 193 & 0.3 & 1 & 1 & \\
\hline $30-44$ & 1719 & 2.2 & 7.12 & 7.50 & 6.46 to 8.70 \\
\hline $45-64^{*}$ & 3937 & 5.2 & 16.96 & 18.05 & 15.62 to 20.86 \\
\hline$\geq 65^{*}$ & 2444 & 3.8 & 12.27 & 14.84 & 12.82 to 17.19 \\
\hline
\end{tabular}

Year and region were not included in the adjusted model.

* Boundary at 60 years for women.

†Adjusted for age and gender. 
Figure 2 Hospitalization rates of upper gastrointestinal haemorrhage by Regional Government Office. (A) Nonvariceal haemorrhage. (B) Variceal haemorrhage.
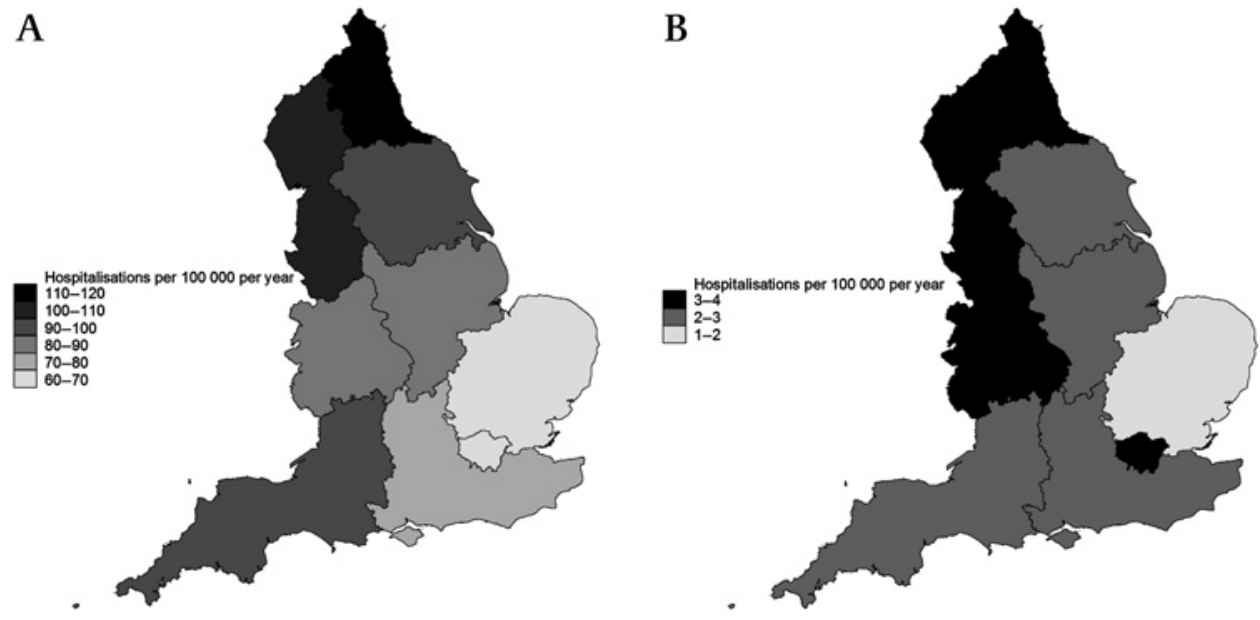

than non-variceal haemorrhage ( $R R$ for non-variceal haemorrhage $2.00,95 \%$ CI 1.98 to 2.03 ; RR for variceal haemorrhage $2.49,95 \%$ CI 2.32 to 2.67$)$.

\section{Univariable and bivariable analysis}

Crude hospitalization rates were higher in areas of greater deprivation, in older age groups and in men (tables 1 and 2). The regional hospitalization rates for variceal and non-variceal haemorrhage are shown in figure 2, with higher rates of hospitalization in the north of the country. The increase in hospitalization with deprivation was observed in all regions and was of far greater magnitude than any regional differences for both variceal and non-variceal bleeds (see figure 3, only non-variceal bleeds shown). The gradient was also present in all age strata (figure 4, only non-variceal bleeds shown). During the study period, there was only a slight year-on-year change in hospitalization rates. Cross-tabulations of crude rates by age group, gender, procedures and associated diagnoses are shown in table 3 .

\section{Multivariate analysis}

Incidence RRs of hospitalization by socioeconomic status were adjusted for age and sex using Poisson regression, and this further increased the difference between the least and most

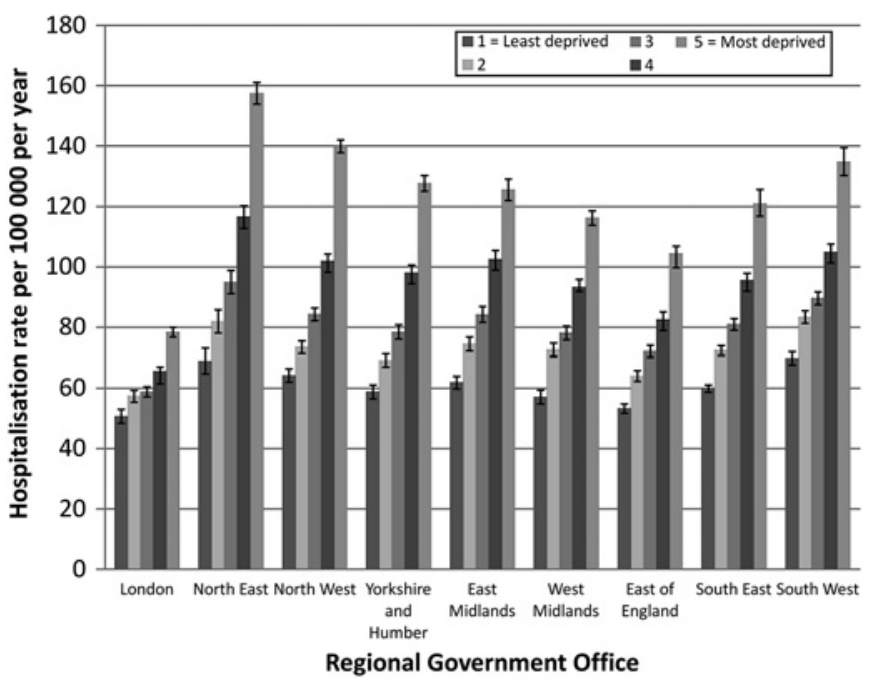

Figure 3 Average annual non-variceal hospitalization rate by quintiles of the Indices of Multiple Deprivation 2007 for each government office. deprived quintiles for non-variceal and variceal haemorrhage (tables 1 and 2). The inclusion of region or year in the model did not alter the estimates. However, a likelihood ratio test for an interaction between year and socioeconomic status demonstrated that there was strong evidence for an increase in inequality over the study period (non-variceal $p<0.0001$, variceal $\mathrm{p}=0.0068$; see figure 5 , only non-variceal haemorrhage shown).

There was no association between socioeconomic status and adjusted 28-day mortality for non-variceal haemorrhage $(p=0.07$, likelihood ratio test for association), and although, for variceal haemorrhage, 28-day mortality increased for some quintiles ( $p=0.004$, likelihood ratio test for association), there was no clear pattern or trend observed with increasing deprivation (table 4).

To further test the validity of our model, we went on to a series of subgroup and sensitivity analyses. The hospitalization gradient by deprivation was found in all subgroups of diagnoses associated with non-variceal haemorrhage admissions (table 5), and, consistent with the main analysis, the 28-day case death did not reduce by deprivation (table 6).

The first sensitivity analysis expanded the definition of variceal haemorrhage, and this reduced the magnitude of the association slightly, but the comparison of most to least deprived quintiles still showed a significant difference (RR 2.60, 95\% CI

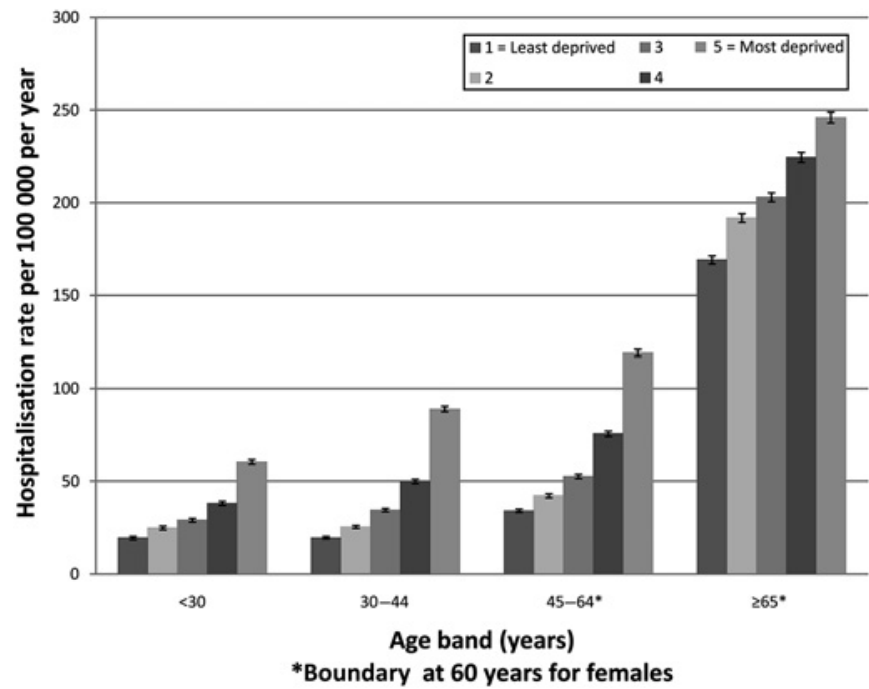

Figure 4 Average annual non-variceal hospitalization rate by quintiles of the Indices of Multiple Deprivation 2007 for each age band. 
Table 3 Crude hospitalization rates per 100000 population (95\% Cls)

\begin{tabular}{|c|c|c|c|c|c|c|}
\hline $\begin{array}{l}\text { Quintiles of } \\
\text { deprivation } \\
\text { (IMD 2007) }\end{array}$ & $1=$ Least deprived & 2 & 3 & 4 & $5=$ Most deprived & $\begin{array}{l}\text { Total population } \\
\text { at risk (million } \\
\text { person-years) }\end{array}$ \\
\hline \multicolumn{7}{|l|}{ Age (years) } \\
\hline $30-44$ & $8.13(7.90$ to 8.37$)$ & $10.33(10.07$ to 10.60$)$ & $14.29(13.98$ to 14.60$)$ & 21.64 (21.25 to 22.02$)$ & 38.56 (38.04 to 39.09 ) & 79 \\
\hline $45-64^{*}$ & $17.59(17.25$ to 17.94$)$ & $20.93(20.55$ to 21.30$)$ & 24.15 (23.75 to 24.55$)$ & 31.65 (31.19 to 32.12 ) & $45.82(45.25$ to 46.39$)$ & 76 \\
\hline$\geq 65^{*}$ & $73.50(72.80$ to 74.21$)$ & 86.01 (85.26 to 86.77 ) & 88.91 (88.14 to 89.68 ) & 90.72 (89.93 to 91.51$)$ & 93.16 (92.35 to 93.98$)$ & 65 \\
\hline Female & 48.81 (48.24 to 49.38 ) & 57.70 (57.09 to 58.33$)$ & $62.44(61.80$ to 63.09$)$ & $69.90(69.21$ to 70.59$)$ & 82.82 (82.05 to 83.59$)$ & 150 \\
\hline Upper GI endoscopy & 51.15 (50.57 to 51.74$)$ & 60.42 (59.78 to 61.05$)$ & 65.86 (65.20 to 66.53$)$ & 74.67 (73.96 to 75.39$)$ & 91.45 (90.65 to 92.26$)$ & \\
\hline Therapeutic endoscopy & 8.35 (8.12 to 8.59$)$ & 9.76 (9.51 to 10.02 ) & $10.48(10.22$ to 10.75$)$ & 11.57 (11.29 to 11.85$)$ & $13.79(13.48$ to 14.11$)$ & \\
\hline Upper GI surgery & $2.90(2.76$ to 3.04$)$ & 3.32 (3.18 to 3.48 ) & $3.56(3.41$ to 3.72$)$ & 4.14 (3.97 to 4.31$)$ & $4.78(4.60$ to 4.97$)$ & \\
\hline Gastric ulcer & 10.07 (9.81 to 10.33$)$ & 11.95 (11.67 to 12.24$)$ & $12.52(12.23$ to 12.81$)$ & 14.17 (13.86 to 14.48$)$ & 16.82 (16.48 to 17.17$)$ & \\
\hline Duodenal ulcer & 13.16 (12.86 to 13.46$)$ & 15.38 (15.06 to 15.71$)$ & $16.57(16.24$ to 16.90$)$ & $17.85(17.50$ to 18.20$)$ & 20.90 (20.52 to 21.29$)$ & \\
\hline Varices & 2.87 (2.74 to 3.02 ) & 3.48 (3.33 to 3.64$)$ & $3.99(3.83$ to 4.16$)$ & $4.92(4.74$ to 5.11$)$ & 7.28 (7.05 to 7.51$)$ & \\
\hline Malignancy & $3.00(2.86$ to 3.15$)$ & 3.45 (3.30 to 3.61$)$ & $3.60(3.45$ to 3.76$)$ & $3.54(3.39$ to 3.70$)$ & 3.71 (3.55 to 3.88 ) & \\
\hline $\begin{array}{l}\text { Population at risk } \\
\text { over whole study } \\
\text { period (millions) }\end{array}$ & 57 & 58 & 58 & 56 & 54 & \\
\hline
\end{tabular}

IMD 2007, Indices of Multiple Deprivation 2007; Gl, gastrointestinal.

2.44 to 2.76). The second sensitivity analysis restricted the definition of non-variceal haemorrhage to admissions coded with an intervention or death, and following this, the socioeconomic gradient was still apparent (RR 1.92 (95\% CI 1.89 to 1.95), adjusted for age and sex).

The third sensitivity analysis was stratified by initial admission and subsequent readmission. Restricting to the first admission for each patient did not substantially alter the gradients by deprivation (supplementary tables A and B). However, there was a steeper gradient by deprivation for readmissions for both non-variceal haemorrhage (adjusted RR

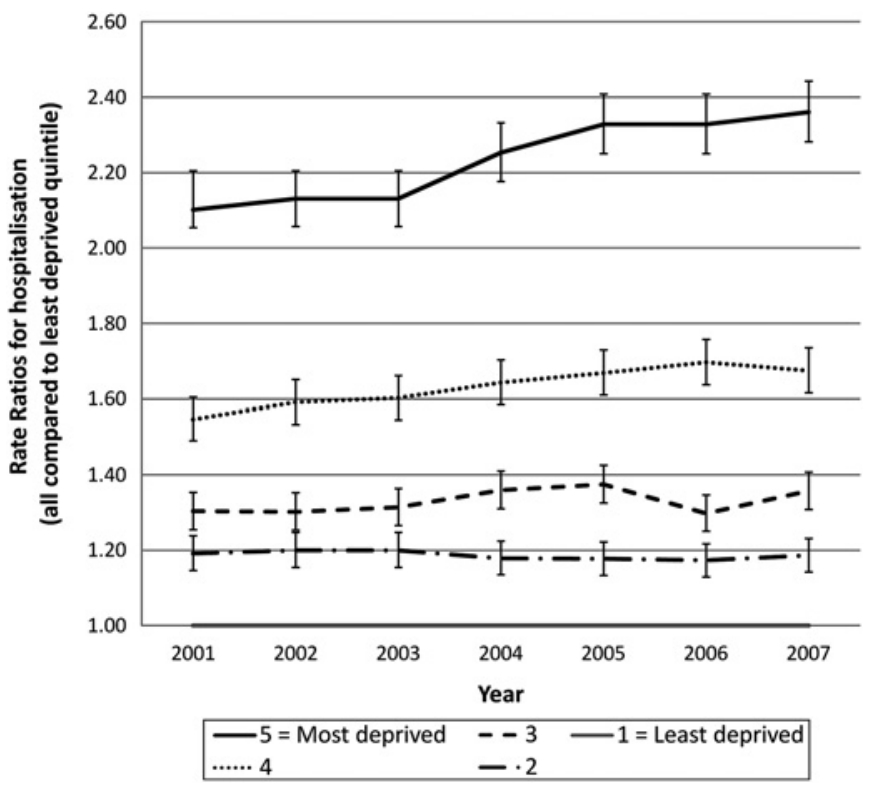

Figure 5 Age- and sex-adjusted hospitalization RRs for non-variceal haemorrhage by year for each quintile of deprivation compared to the least deprived quintile. comparing most to least deprived 3.25 (3.15-3.36)) and variceal haemorrhage (adjusted RR comparing most to least deprived 2.69 (2.45-2.94)). Finally, excluding patients with a previous admission related to alcohol also did not alter any of the overall deprivation gradients.

\section{DISCUSSION}

Those who live in the most disadvantaged areas of England have a two to three times higher rate of hospitalization for upper gastrointestinal haemorrhage compared to people living in the most affluent areas. It is improbable that living in a particular residential area itself causes upper gastrointestinal haemorrhage but, rather, that more deprived people have risk factors that more affluent people have been able to avoid. According to our

Table 4 Crude and adjusted ORs for 28-day mortality in each deprivation quintile

\begin{tabular}{llll}
\hline IMD 2007 quintile & $\begin{array}{l}\text { 28-Day } \\
\text { deaths }(\mathbf{n})\end{array}$ & $\begin{array}{l}\text { Crude } \\
\text { OR }\end{array}$ & $\begin{array}{l}\text { Adjusted OR* } \\
\text { (95\% Cl) }\end{array}$ \\
\hline $\begin{array}{l}\text { Non-variceal haemorrhage } \\
\text { 1=Least } \\
\text { deprived }\end{array}$ & 3947 & 1 & 1 \\
2 & & & \\
3 & 4819 & 1.02 & $1.04(0.99$ to 1.08$)$ \\
4 & 5083 & 0.97 & $1.06(1.01$ to 1.11$)$ \\
5=Most deprived & 5209 & 0.86 & $1.06(1.02$ to 1.11$)$ \\
$\begin{array}{l}\text { Variceal haemorrhage } \\
\text { 1=Least }\end{array}$ & 5348 & 0.69 & $1.04(0.99$ to 1.08$)$ \\
deprived & 195 & 1 & 1 \\
2 & & & \\
3 & 255 & 1.13 & $1.14(0.92$ to 1.40$)$ \\
4 & 268 & 0.96 & $1.00(0.81$ to 1.22$)$ \\
5=Most deprived & 396 & 1.26 & $1.33(1.10$ to 1.61$)$ \\
& 503 & 1.12 & $1.23(1.03$ to 1.49$)$ \\
\hline
\end{tabular}

Linked HES/ONS mortality records are currently provided on a provisional basis. An issue has arisen whereby a small number of mortality records may have been incorrectly rejected. The algorithm that links HES to ONS mortality is currently being amended to rectify this issue, which affects approximately 1000 mortality records or about $0.02 \%$ of the total. ${ }^{*}$ Adjusted by logistic regression for age and sex. 
Table 5 Age- and gender-adjusted RRs for upper gastrointestinal haemorrhage admission by associated diagnoses

\begin{tabular}{llllll}
\hline Age- and gender-adjusted RR (95\% Cls) & & & \\
\hline IMD 2007 quintiles & $\mathbf{1 = L e a s t ~ d e p r i v e d ~}$ & $\mathbf{2}$ & $\mathbf{3}$ & $\mathbf{4}$ & $\mathbf{5}=$ Most deprived \\
\hline Gastritis/duodenitis & 1 & $1.21(1.16$ to 1.26$)$ & $1.39(1.33$ to 1.44$)$ & $1.71(1.64$ to 1.78$)$ & $2.22(2.14$ to 2.31$)$ \\
Mallory-Weiss syndrome & 1 & $1.22(1.15$ to 1.29$)$ & $1.39(1.31$ to 1.46$)$ & $1.79(1.70$ to 1.89$)$ & $2.61(2.48$ to 2.74$)$ \\
Oesophagitis & 1 & $1.16(1.11$ to 1.21$)$ & $1.33(1.28$ to 1.39$)$ & $1.57(1.51$ to 1.63$)$ & $2(1.92$ to 2.08$)$ \\
Gastric ulcer & 1 & $1.16(1.11$ to 1.21$)$ & $1.26(1.20$ to 1.31$)$ & $1.54(1.48$ to 1.61$)$ & $1.9(1.83$ to 1.98$)$ \\
Duodenal ulcer & 1 & $1.16(1.12$ to 1.21$)$ & $1.30(1.25$ to 1.35$)$ & $1.52(1.46$ to 1.57$)$ \\
Malignancy & 1 & $1.16(1.04$ to 1.29$)$ & $1.22(1.09$ to 1.35$)$ & $1.31(1.17$ to 1.46$)$ & $1.89(1.82$ to 1.96$)$ \\
\hline
\end{tabular}

findings, if the whole population experienced the same levels of risk as did the most affluent, we estimate that up to 10000 admissions, costing a total of at least $£ 20$ million (US\$34 million), ${ }^{6}$ and over 1000 deaths could be prevented each year in England. As the causes of many upper gastrointestinal haemorrhages are known and are modifiable, the prevention of these admissions and deaths is potentially achievable.

Our study provides a complete national picture for England of the increased risk of upper gastrointestinal haemorrhage hospitalization associated with areas of higher deprivation and, therefore, provides the first demonstration that this steep gradient is present in all regions of the country and is independent of age and sex. Our large study population allows us for the first time to demonstrate socioeconomic associations with both variceal and non-variceal haemorrhage, and by including all hospital admissions for upper gastrointestinal bleeding in England, we have minimized the effect of selection bias and have adequately adjusted for the effects of demographic differences across England. There are, of course, weaknesses in the methodology of using small area statistics. First, by assessing deprivation at lower super output area level, we risk incorrectly assigning an area's average risk of deprivation to individuals with very different personal economic circumstances. This may explain the lesser association with deprivation observed in London, where the close proximity of rich and poor households might have increased the possibility of this type of misclassification. However, although the effects of this ecological bias could have been in either direction and were unknown, we believe that the misclassification was most likely to be nondifferential, and the effect would therefore be to reduce observed associations. The other possible error from using small area statistics was some residual confounding by age due to the use of broad age categories chosen to match those in ONS denominator data. However, this residual confounding is unlikely to explain the association we observed, since the age adjustment that was possible increased the strength of the association rather than reduced it. Apart from small area statistics, the other potential weakness in our study is the accuracy of routine hospital admissions coding. However, it seems unlikely that coding inaccuracies would have been associated with the socioeconomic status of a patient, so any coding errors would have reduced rather than caused the magnitude of the association we observed. Furthermore, this error is likely to be small, as the most recent audit of UK hospital data shows accuracy approaching $90 \%{ }^{7}$ and the incidence of peptic ulcer haemorrhage in HES data from 1992 to 1995 has been shown to be comparable to the 1993 regional British Society of Gastroenterology (BSG) audit (32 vs 29 per 100000 per year, respectively). One specific concern about the coding in our study is the possibility of underreporting of variceal haemorrhage, which we found to be less frequently reported than in the recent BSG audit. ${ }^{8}$ However, our finding was similar to that of the 1993 BSG audit (4\%) and other studies, ${ }^{9}{ }^{10}$ and the socioeconomic gradient was robust against a sensitivity analysis that broadened the definition of variceal bleeding. Our other concern about coding is that over-reporting of cases that were not real bleeds may have occurred. However, restricting cases to only those with a recorded intervention (such as endoscopy) or outcome (such as death) did not substantially alter the association with socioeconomic status.

Previous studies support the validity of our findings; Button et $a l^{3}$, in a recent study from Wales, used routine data to demonstrate a crude twofold difference in upper gastrointestinal bleed hospitalization between the least and most deprived. However, their study was 10 times smaller than ours and did not investigate if this inequality was confounded by type of bleed, region, age, gender or year. Blatchford et $a l^{2}$ in a regional study of 1882 patients in the northwest of Scotland 15 years ago, found no association of case death with socioeconomic status measured by Carstairs score but observed a twofold increase in the unadjusted incidence of upper gastrointestinal haemorrhage between the least and most affluent quartiles. We have expanded on these studies and used a more comprehensive measure of deprivation than the latter to demonstrate that this gradient is present in all regions of the country, for all ages, both men and women, and is steeper for variceal than non-variceal haemorrhage. Our study also found a north-south gradient in crude hospitalization that was mostly explained by deprivation, and this is similar to the report of Woods et al, ${ }^{11}$ who identified a north-south gradient in all-cause mortality that was also mostly attributable to deprivation.

Table 6 Age- and gender-adjusted ORs for 28-day mortality in each deprivation quintile by associated diagnoses

\begin{tabular}{|c|c|c|c|c|c|}
\hline \multicolumn{6}{|c|}{ Age- and gender-adjusted OR for case death $(95 \% \mathrm{Cls})$} \\
\hline IMD 2007 quintiles & $1=$ Least deprived & 2 & 3 & 4 & $5=$ Most deprived \\
\hline Gastritis/duodenitis & 1 & $1.09(0.90$ to 1.31$)$ & $1.09(0.90$ to 1.32$)$ & $1.14(0.94$ to 1.37$)$ & $1.07(0.88$ to 1.29$)$ \\
\hline Mallory-Weiss syndrome & 1 & $0.87(0.58$ to 1.31$)$ & $1.18(0.81$ to 1.73$)$ & $1.10(0.75$ to 1.61$)$ & 1.15 (0.79 to 1.68$)$ \\
\hline Gastric ulcer & 1 & $1.01(0.87$ to 1.17$)$ & $1.04(0.90$ to 1.20$)$ & $1.05(0.91$ to 1.21$)$ & $1.22(1.06$ to 1.40$)$ \\
\hline Duodenal ulcer & 1 & $1.11(1.00$ to 1.25$)$ & $1.10(0.99$ to 1.23$)$ & $1.17(1.04$ to 1.30$)$ & 1.19 (1.06 to 1.33$)$ \\
\hline Malignancy & 1 & $1.13(0.90$ to 1.41$)$ & $0.98(0.78$ to 1.23$)$ & $1.06(0.84$ to 1.33$)$ & 1.21 (0.96 to 1.52 ) \\
\hline
\end{tabular}

Linked HES/ONS mortality records are currently provided on a provisional basis. An issue has arisen whereby a small number of mortality records may have been incorrectly rejected. The algorithm that links HES to ONS mortality is currently being amended to rectify this issue, which affects approximately 1000 mortality records or about $0.02 \%$ of the total. 
Deprivation influenced mortality in our study, not nearly to the extent that it influenced hospitalizations. This reassuringly suggests that admissions from deprived areas are receiving comparable hospital care to those from less deprived areas; however, it also implies that the focus for reducing inequality in upper gastrointestinal bleeding should be to prevent and treat its causes rather than further modify acute services. This is potentially achievable, as many risk factors are already known and modifiable. For example, $H$ pylori, which is simple to eradicate, is known to have a higher prevalence in deprived areas from crowded childhood living conditions. ${ }^{12}$ Other lifestyle risk factors for causes of bleeding such as smoking, larger waist circumferences and alcohol-related diseases are also more common in populations with higher levels of deprivation and could be modifiable through effective public health interventions. ${ }^{13-15}$ However, in our subgroup analysis, we excluded previous alcohol-related admissions, and we found that this did not reduce any of the inequality in bleeding occurrence. Another potential cause of the inequality we have observed is that harmful prescribing practices have been shown to be increased for people with lower socioeconomic status ${ }^{16}$; for example, lower skilled occupations had a higher chronic NSAID use (OR 1.4) than did skilled workers despite a higher prevalence of dyspepsia. ${ }^{17}$ This latter study included over-the-counter NSAID use, so as proton pump inhibitors are now easily obtainable without prescription, we speculate that it might be responsible to encourage or strongly recommend the supply of proton pump inhibitors with NSAIDS in deprived areas.

In conclusion, we have demonstrated that people from areas of greater deprivation have higher rates of hospitalization for upper gastrointestinal haemorrhage than what are explained by random error or measured confounding. There are, therefore, opportunities for interventions to prevent disease in more deprived areas and to reduce the 10000 excess admissions and 1000 excess deaths associated with deprivation and, thus, make the most of our currently scarce economic resources.

Funding Colin Crooks is a research fellow supported by a Medical Research Council fellowship. Tim Card is a clinical associate professor and a consultant gastroenterologist supported by a Walport senior lectureship. Joe West is a clinical associate professor and a consultant gastroenterologist supported by an National Institute for Health Research (NIHR) clinician scientist fellowship. These funding bodies had no role in the collection, analysis or interpretation of data.

Competing interests The only competing interest is that Tim R Card is married to an employee of AstraZeneca. Otherwise, there are no potential competing interests to declare.

Ethical approval Ethical approval was obtained through the Database Monitoring Subgroup and the Office of National Statistics Microdata Release Panel as part of the standard Hospitals Episode Statistics approval process.
Contributors All authors were involved in the study design and concept interpretation of results and editing of manuscript. Colin Crooks analysed the data set and wrote the initial manuscript draft. Joe West obtained funding and ethical approval for the data set. All authors had full access to all of the data (including statistical reports and tables) in the study and can take responsibility for the integrity of the data and the accuracy of the data analysis.

Provenance and peer review Not commissioned; externally peer reviewed.

\section{REFERENCES}

1. Marmot M, Atkinson T, Bell J, et al. Strategic review of health inequalities in England post-2010. The Marmot review, 2010. http://www.marmotreview.org/ AssetLibrary/pdfs/Reports/FairSocietyHealthyLives.pdf (accessed 5 Nov 2010).

2. Blatchford 0, Davidson LA, Murray WR, et al. Acute upper gastrointestinal haemorrhage in west of Scotland: case ascertainment study. BMJ 1997; 315:510-14.

3. Button LA, Roberts SE, Evans PA, et al. Hospitalized incidence and case fatality for upper gastrointestinal bleeding from 1999 to 2007: a record linkage study. Aliment Pharmacol Ther 2011;33:64-76.

4. Communities and Local Government. The English indices of deprivation 2007 Communities and Local Goverment Publications, 2007. http://www.communities.gov. uk/documents/communities/pdf/733520.pdf (accessed 29 Apr 2011).

5. Azim L, Henryk 0, Daniel E. Compendium of clinical and health indicators: data definitions and user guide for computer files. National Centre for Health Outcomes Development, 2008; http://www.nchod.nhs.uk/NCHOD/ePublish.nsf/ fe55addc24ce637165256cd20029197e/8d9a57ccd4afdc1365257561003acf82/ \$FILE/User\%20Guide\%202008\%20(December).doc (accessed 23 Dec 2008).

6. Viviane A, Alan BN. Estimates of costs of hospital stay for variceal and nonvariceal upper gastrointestinal bleeding in the United States. Value Health 2008;11:1-3.

7. Audit Commission. Improving data quality in the NHS. Annual report on the PbR assurance programme, 2010; http://www.audit-commission.gov.uk/ SiteCollectionDocuments/Downloads/26082010pbrnhsdataqualityreport.pdf (accessed 5 Nov 2010).

8. Hearnshaw SA, Logan RF, Lowe D, et al. Acute upper gastrointestinal bleeding in the UK: patient characteristics, diagnoses and outcomes in the 2007 UK audit. Gut 2011;60:1327-35.

9. Rockall TA, Logan RF, Devlin HB, et al. Incidence of and mortality from acute upper gastrointestinal haemorrhage in the United Kingdom. Steering Committee and members of the National Audit of Acute Upper Gastrointestinal Haemorrhage. BMJ 1995;311:222-6.

10. van Leerdam ME. Epidemiology of acute upper gastrointestinal bleeding. Best Pract Res Clin Gastroenterol 2008;22:209-24

11. Woods LM, Rachet B, Riga M, et al. Geographical variation in life expectancy at birth in England and Wales is largely explained by deprivation. J Epidemiol Community Health 2005:59:115-20.

12. Sitas F, Forman D, Yarnell JW, et al. Helicobacter pylori infection rates in relation to age and social class in a population of Welsh men. Gut 1991;32:25-8.

13. Hemmingsson T, Lundberg I, Romelsjo A, et al. Alcoholism in social classes and occupations in Sweden. Int J Epidemiol 1997;26:584-91.

14. Goddard E. General household survey 2006: smoking and drinking among adults 2006. Office for National Statistics, 2008. http://www.statistics.gov.uk/downloads/ theme compendia/GHS06/GHS2006.zip (accessed 04 Nov 2010).

15. Huerta MC, Borgonovi F. Education, alcohol use and abuse among young adults in Britain. Soc Sci Med 2010;71:143-51.

16. Odubanjo $\mathbf{E}$, Bennett $K$, Feely $\mathrm{J}$. Influence of socioeconomic status on the quality of prescribing in the elderly - a population based study. Br J Clin Pharmacol 2004; 58:496-502.

17. Rossignol M, Abouelfath A, Lassalle $\mathrm{R}$, et al. The CADEUS study: burden of nonsteroidal anti-inflammatory drug (NSAID) utilization for musculoskeletal disorders in blue collar workers. Br J Clin Pharmacol 2009:67:118-24. 